\title{
On Predicting Roller Milling Performance IV: Effect of Roll Disposition on the Particle Size Distribution from First Break Milling of Wheat
}

\author{
Chaoying Fang and Grant M. Campbell* \\ Satake Centre for Grain Process Engineering, Department of Chemical Engineering, \\ UMIST, Manchester, M60 1QD, UK \\ Received 16 October 2001
}

\begin{abstract}
The breakage equation for roller milling allows prediction of the output particle size distribution from the feed particle size distribution in terms of a breakage function. Breakage functions were determined for First Break milling of hard and soft wheats under four roll dispositions: Sharp-to-Sharp (S-S), Sharp-toDull (S-D), Dull-to-Sharp (D-S) and Dull-to-Dull (D-D). The breakage functions were then used to predict the particle size distribution resulting from milling whole wheat samples at different roll gaps, for comparison with experimental results. First Break milling of both hard and soft wheat samples under a S$\mathrm{S}$ disposition gave an even distribution of particle sizes over the range 250-2000 $\mu \mathrm{m}$, which could be described by linear breakage functions. The effect of changing roll gap was to change the slope of the line i.e. to change the balance between small and large particles, with larger roll gaps giving a greater proportion of large panicles. Milling under S-D, D-S and D-D dispositions gave progressively more 'Ushaped' distributions; these were described by quadratic functions that indicated large quantities of small and large particles, but fewer in the middle size range. Again, increasing roll gap changed the balance towards more large particles, but had little effect on the quantity of particles in the middle size range. Predictions of output cumulative particle size distributions using the breakage equation gave excellent agreement with independently derived experimental results, with $R^{2}$ in excess of 0.99 in all cases. The trend in wheat quality testing is to measure distributions of single kernel parameters. The breakage equation approach allows the link to be made between distributions of single kernel parameters and milling performance.
\end{abstract}

(C) 2003 Published by Elsevier Science Ltd

Keywords: first break milling, roll disposition, size distribution, breakage equation.

\section{INTRODUCTION}

Milling of wheat into flour can be viewed as 'the evolution of the particle size distribution', as particles are progressively broken by roller mills and separated by plansifters. The process starts with First Break milling, in which fluted rolls operating under a differential open the wheat grains and begin the process of separating the more nutritious endosperm from the protective bran layers. The use of fluted rolls has the benefit that the bran particles tend to

\footnotetext{
* Corresponding author. Tel: +44(0) 1612004472 ; Fax: +44(0) 161200 4399; E-mail: g.campbell@umist.ac.uk
}

stay large, while the more friable endosperm breaks into smaller particles, allowing separation of bran from endosperm based on size using plansifters. Repeated breakage and separation in the 'gradual reduction process' allows highly efficient recovery of flour, relatively free from bran contamination ${ }^{1,2}$.

The particle size distribution resulting from First Break milling directly affects the subsequent process configuration and machine settings, and thus determines the effectiveness of the milling process ${ }^{1,3}$. First Break is thus a critical control point in the milling process. A wide size range of particles is produced from First Break, from smaller than $200 \mu \mathrm{m}$ to larger than $2000 \mu \mathrm{m}$. The distribution of particle sizes 
depends on the interaction between the characteristics of the grist and the roll design and operation. The ability to predict and control the output particle size distribution from First Break milling is thus critical to the flour milling process.

Wheat kernels break independently during roller milling ${ }^{4}$. The relationship between input and output mass-based particle size distributions for a roller milling operation can therefore be described by ${ }^{5,6}$

$$
\rho_{2}(x)=\int_{0}^{\infty} \rho(x, D) \rho_{1}(D) d D
$$

where $\rho_{1}(D)$ is the probability density function describing the input particle size distribution and $\rho_{2}(x)$ is the probability density function describing the output particle size distribution. $\rho(x, D)$ is the breakage function, which describes the probability of creating a output particle of size $x$ from an inlet particle of size $D$ (strictly speaking, the probability of creating a particle in the range $x, x+d x$ from a particle initially of size $D=\rho(x, D) d x$ ). If the breakage function is known, then the output particle size distribution can be predicted for any distribution of inlet particle sizes. This simplifies the study of First Break milling to determining the form of the breakage function. The cumulative form of the breakage function is given by

$$
B(x, D)=\int_{0}^{x} \rho(x, D) d x
$$

Similarly, the proportion of output material smaller than $x$ is given by

$$
P(x)=\int_{0}^{x} \rho_{2}(x) d x
$$

The cumulative form of the breakage equation is therefore

$$
P(x)=\int_{0}^{\infty} B(x, D) \rho_{1}(D) d D
$$

The breakage equation approach has been applied for some years in other industries in which comminution is important, most notably minerals processing. Austin ${ }^{7}$ reviewed the development of the theory in this area and identified breakage equations appropriate for various types of mill, including batch mills, continuous retention mills such as hammer and ball mills, and once-through mills such as roller mills. Various forms of breakage function have been identified, suitable for different mills and materials, such as

$$
B(x, D)=\phi\left(\frac{x}{D}\right)^{\gamma}+(1-\phi)\left(\frac{x}{D}\right)^{\beta}
$$

where $\phi, \gamma$, and $\beta$ are fitted coefficients ${ }^{7-11}$. Rajendran Nair ${ }^{12}$, studying breakage behaviour of mineral materials with different hardness in a circular fluid energy mill, found the above coefficients to be related to the hardness of the materials.

Little work on the form of the breakage function suitable for roller milling using fluted rolls has been reported. Most previous work was based on other milling methods, such as hammer milling ${ }^{13}$, ball milling ${ }^{14}$, impact crushing ${ }^{15}$, the Szego mill ${ }^{16}$, the roller table mill ${ }^{17}$ and smooth roll crushers ${ }^{8-10}$. Materials investigated include coals, rocks, quartz and other mineral materials. Scanlon and Lamb ${ }^{13}$ used a model starch-based viscoelastic material which was essentially homogeneous.

The breakage function depends on the milling method and the material being processed. $\mathrm{Krogh}^{15}$ studied crushing characteristics of three mineral materials and found that the breakage function is dependent on the crystal structure. Wheat is much more structurally complex than coal or other mineral materials commonly processed by comminution, comprising endosperm, bran and germ, each with different mechanical properties ${ }^{18-22}$. Gotsis and Trass ${ }^{16}$ compared the milling performance of coal and wheat in a Szego mill and found that rotational speed and feed rate had the opposite effect on milling of wheat compared with coal.

Campbell and coworkers ${ }^{5,6}$ showed that the breakage function for roller milling could be determined by milling narrow size fractions of wheat separated by thickness using slotted sieves. They found that under Sharp-to-Sharp milling the breakage function could be described adequately by a linear function in $x$ over a range of output particle sizes from 250-2000 $\mu \mathrm{m}$, and a quadratic function of the milling ratio, $G / D$ (the ratio of roll gap to inlet particle size). They fitted a cumulative breakage function of the form

$$
\begin{aligned}
B(x, D)= & a_{0}+b_{0} x+c_{0} x^{2}+\left(a_{1}+b_{1} x+c_{1} x^{2}\right)\left(\frac{G}{D}\right) \\
& +\left(a_{2}+b_{2} x+c_{2} x^{2}\right)\left(\frac{G}{D}\right)^{2}
\end{aligned}
$$

Differentiation of this cumulative function with respect to $x$ gives a breakage function that is linear 
in $x$. Bunn et $a l^{23}$ confirmed that this linear relationship adequately described breakage of a wide range of wheat varieties under Sharp-to-Sharp milling. They showed that the slope of the breakage function at a given milling ratio was related to wheat hardness, and identified an additional parameter describing wheat breakage: Sensitivity. The particle size distribution resulting from milling sensitive wheats varies significantly with changes in the roll gap, while insensitive wheat varieties do not respond so readily to changes in the roll gap. Preferred UK milling varieties tend to be hard and sensitive.

Fang and Campbell ${ }^{24}$ investigated the effect of roll disposition (Sharp-to-Sharp, S-S; Sharp-to-Dull, S-D; Dull-to-Sharp, D-S; and Dull-to-Dull, D-D) on the breakage of wheat kernels during First Break roller milling and found that different dispositions produce different particle size distributions, which they discussed in terms of the fracture mechanics of wheat breakage. Figure 1 illustrates the four roll dispositions. Because of the wheat structure and the working angles of the roll flutes, the forces acting on the wheat grain engaged between rollers are different in term of direction and magnitude. Under S-S disposition, bran and endosperm break together resulting in a broad and relatively even distribution of particles. Under D-D milling, fracture is primarily compressive, which causes disintegration of the fragile endosperm while leaving the bran relatively intact, resulting in a 'U-shaped' distribution, with many small and large particles, but few in the midsize range. S-D and D-S milling lie between these extremes. The difference in size distribution indicates that the breakage function will take different forms for different roll dispositions.

The objective of the current study was to identify the forms of the breakage function suitable to describe wheat breakage under First Break roller milling for hard and soft wheats milled under different roll dispositions, and then to demonstrate the predictive ability of the breakage equation.

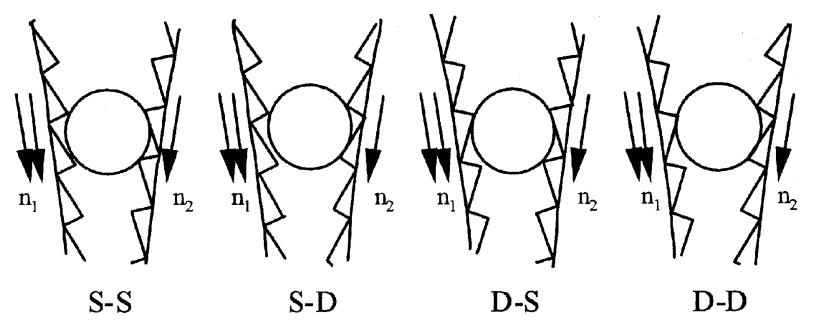

Figure 1 Four types of roll disposition: Sharp-to-Sharp (S-S); Sharp-to-Dull (S-D); Dull-to-Sharp (D-S); and Dull-to-Dull (D-D). From Fang and Campbell ${ }^{24}$.
These quantitative predictions aim to complement the more qualitative fracture mechanics discussions presented previously ${ }^{24}$.

\section{MATERIALS AND METHODS}

Wheat was milled at different roll gaps using the Satake STR-100 test roller mill as described previously $^{1,24}$. Hereward, a hard wheat (bulk density $79.4 \mathrm{~kg} \mathrm{hl}^{-1}$, protein content $\left.14.6 \% \mathrm{db}\right)$, and Consort, a soft wheat (bulk density $74.2 \mathrm{~kg} \mathrm{hl}^{-1}$, protein content $10 \cdot 6 \% \mathrm{db}$ ), both from $1999 \mathrm{UK}$ harvest, were used in this study. The average kernel hardness of the two samples as measured by the Perten SKCS Model 4100 (Perten Instruments AB, Sweden) was 50.6 for Hereward and $10 \cdot 8$ for Consort.

Both wheats were separated into six narrow size fractions by thickness using slotted sieves in a Satake SPU 125AU Purifier (Satake Corporation, Japan). The purifier is a tandem, triple deck purifier which uses a combination of sieving and aspiration to separate flour stocks. In this work, it was used without aspiration and with slotted metal plates. The width of slots were 2, 2.25, 2.5, 2.75, 3 and $3.25 \mathrm{~mm}$, which separated the wheat by thickness (third longest dimension) into seven fractions. The wheat grains larger than $3.25 \mathrm{~mm}$ in thickness were further separated with a $3.5 \mathrm{~mm}$ slotted sieve on a Simon sifter. The fractions larger than $3.5 \mathrm{~mm}$ and smaller than $2 \mathrm{~mm}$ were discarded because of the significant amount of broken or non-wheat material. Table I shows the size fractions of the separated Hereward and Consort wheat.

Each size fraction was conditioned overnight to $16 \%$ moisture content wb, then separated into $100 \mathrm{~g}$ samples, each stored in a plastic bag. Samples were milled on the Satake STR-100 test roller mill (Satake Corporation, Japan). The milling was performed under the four roll dispositions illustrated in

Table I Size fractions of Hereward and Consort wheat obtained by separation using slotted sieves

\begin{tabular}{lcr}
\hline Size range $(\mathrm{mm})$ & \multicolumn{2}{c}{$\%$ of sample } \\
\cline { 2 - 3 } & Hereward & Consort \\
\hline $3 \cdot 25-3 \cdot 50$ & $19 \cdot 10$ & $18 \cdot 79$ \\
$3 \cdot 00-3 \cdot 25$ & $20 \cdot 25$ & $17 \cdot 47$ \\
$2 \cdot 75-3 \cdot 00$ & $27 \cdot 34$ & $23 \cdot 32$ \\
$2 \cdot 50-2 \cdot 75$ & $21 \cdot 41$ & $21 \cdot 49$ \\
$2 \cdot 25-2 \cdot 50$ & $9 \cdot 10$ & $13 \cdot 30$ \\
$2 \cdot 00-2 \cdot 25$ & $2 \cdot 81$ & $5 \cdot 63$ \\
\hline
\end{tabular}


Figure 1. Fluted rolls $100 \mathrm{~mm}$ in length with $10 \cdot 5$ flutes per inch were used, with flute angles of $\beta_{s}=21^{\circ}$ and $\beta_{d}=67^{\circ}$. The fast and slow roll speeds were 600 and $222 \mathrm{rpm}$, respectively, giving a differential of $2 \cdot 7$. The mill was operated at a feed rate of $375-500 \mathrm{~kg} / \mathrm{h}$, corresponding to $3750-5000 \mathrm{~kg} /$ $\mathrm{h} \cdot$ metre on a full-length commercial mill. Five roll gaps $(0 \cdot 3,0.4,0.5,0.6$ and $0.7 \mathrm{~mm})$ were used for the milling test. The roll gaps were set using a feeler gauge. A total of 27 milling ratios for each roll disposition and each wheat variety were selected from the combination of six size fractions and five roll gaps to cover the range of milling ratios evenly from 0.074 to 0.329 .

The entire milled stock from each trial was collected for sieve analysis. Samples were sieved on a Simon sifter for 8 minutes using wire mesh sieves of size: 2000, 1700, 1400, 1180, 850, 500 and $212 \mu \mathrm{m}$, along with a bottom pan. Each sieved fraction was weighed to $0.01 \mathrm{~g}$ using an Ohaus Precision Standard balance Model TS4KW (Ohaus Corporation, USA).

Breakage functions were fitted to the data using the procedure of Campbell et al. ${ }^{6}$, for each roll disposition and each wheat variety. For S-D, D-S and D-D milling, cumulative breakage functions that were cubic with respect to $x$ and quadratic with respect to $G / D$ were found to be appropriate, such that equation (6) was modified to:

$$
\begin{aligned}
B(x, D)= & a_{0}+b_{0} x+c_{0} x^{2}+d_{0} x^{3} \\
& +\left(a_{1}+b_{1} x+c_{1} x^{2}+d_{1} x^{3}\right)\left(\frac{G}{D}\right) \\
& +\left(a_{2}+b_{2} x+c_{2} x^{2}+d_{2} x^{3}\right)\left(\frac{G}{D}\right)^{2}
\end{aligned}
$$

Coefficients were fitted by least squares regression using Microsoft Excel (Microsoft Corporation, USA).

The breakage functions were then used to predict the outlet size distribution for the native (unseparated) feed. These predictions were compared with the results of milling native feed samples of both wheat varieties for various roll gaps at each roll disposition. For each wheat variety and each roll disposition, $1.5 \mathrm{~kg}$ of unseparated sample was prepared as native feed. These batches were also conditioned to $16 \%$ moisture content wb, separated into $100 \mathrm{~g}$ samples and milled on the Satake STR100 test roller mill at five roll gaps $(0 \cdot 3,0 \cdot 4,0 \cdot 5,0 \cdot 6$ and $0.7 \mathrm{~mm}$ ) and under the four roll dispositions. Three $100 \mathrm{~g}$ replicate samples were milled at each roll gap and disposition. The coefficient of determination, $R^{2}$, was calculated to compare the predicted cumulative size distributions and actual measured particle size distributions milled from the native feed.

\section{RESULTS AND DISCUSSION}

Figure 2 shows the relationship between the cumulative particle size distribution and the milling ratio $G / D$ at different roll dispositions, for First Break milling of Hereward and Consort. The solid lines are the fitted cumulative breakage function, $B(x, D)$. Clearly, as the milling ratio increases (larger gap or smaller feed particle size), the proportion of broken material smaller than any given size, $x$, decreases i.e. a larger milling ratio gives less breakage, as expected. The variation in the proportion of material smaller than $x$ with milling ratio can be described as a quadratic in $G / D$ for all values of $x$.

Figure 2 also shows that going from S-S, S-D, D-S through to D-D, the curves become more clustered together in the medium size range from $850 \mu \mathrm{m}$ to $1400 \mu \mathrm{m}$ for both varieties. This indicates less material in these size ranges, and more material at the extremes i.e. more large particles and more small particles, but fewer in the mid-size range, as reported by Campbell et al. ${ }^{1}$ and Fang and Campbell ${ }^{24}$. As milling ratio increases, the balance between small and large particles changes in favour of a greater proportion of larger particles. Fang and Campbell $^{24,25}$ discuss in greater detail the reasons for these different breakage patterns in terms of fracture mechanics and the mechanical properties of bran and endosperm.

As reported by Campbell et al. ${ }^{6}$, the cumulative breakage function for the S-S disposition takes the form as shown in equation (6), quadratic in both $x$ and $G / D$. For the other three roll dispositions, S-D, D-S and D-D, it has been found that the form of the cumulative breakage function given in equation (7), cubic in $x$, described the data more appropriately. Table II shows the coefficients fitted for both Hereward and Consort at each roll disposition, along with the values of the coefficient of determination, $R^{2}$. These were greater than 0.97 in all cases, indicating that these forms of the cumulative breakage function describe the data well. This is confirmed by inspection of the solid lines plotted from these coefficients on Figure 2, which coincide closely with the experimental data. 

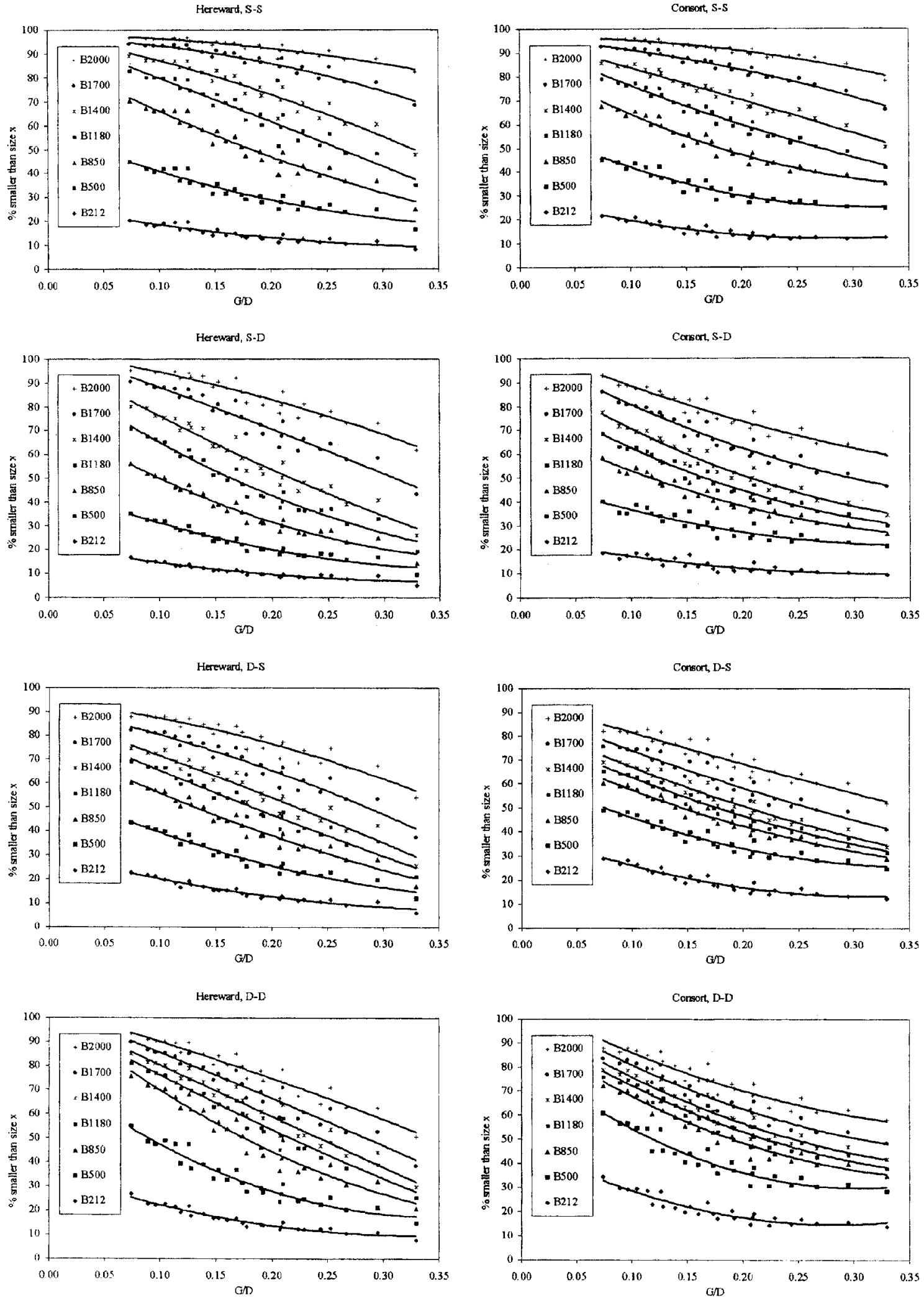

Figure 2 Cumulative particle size distribution vs. milling ratio, G/D, at different roll dispositions, for First Break milling of Hereward and Consort. 
Table II Coefficients of $B(x, D)$ and $R^{2}$ for First Break milling of Hereward and Consort

\begin{tabular}{|c|c|c|c|c|}
\hline \multirow[t]{2}{*}{ Coefficient } & \multicolumn{4}{|c|}{ Disposition } \\
\hline & S-S & S-D & D-S & D-D \\
\hline \multicolumn{5}{|l|}{ Hereward } \\
\hline$a_{0}$ & 2.74 & $-0 \cdot 2876$ & $2 \cdot 980$ & $-11 \cdot 66$ \\
\hline$a_{1}$ & -62.91 & $55 \cdot 16$ & $-5 \cdot 731$ & $67 \cdot 80$ \\
\hline$a_{2}$ & $235 \cdot 32$ & $-150 \cdot 44$ & $-9 \cdot 872$ & -81.59 \\
\hline$b_{0}$ & $0 \cdot 1301$ & $0 \cdot 1066$ & $0 \cdot 1489$ & $0 \cdot 2618$ \\
\hline$b_{1}$ & $-0 \cdot 2977$ & $-0 \cdot 6906$ & $-0 \cdot 6506$ & $-1 \cdot 3432$ \\
\hline$b_{2}$ & $-0 \cdot 1794$ & $1 \cdot 3954$ & 1.0036 & $2 \cdot 0610$ \\
\hline$c_{0}$ & $-4 \cdot 226 \mathrm{E}-05$ & $-1 \cdot 620 \mathrm{E}-05$ & $-8.912 \mathrm{E}-05$ & $-1.912 \mathrm{E}-04$ \\
\hline$c_{1}$ & $1 \cdot 748 \mathrm{E}-04$ & $3 \cdot 513 \mathrm{E}-04$ & $5 \cdot 548 \mathrm{E}-04$ & $1 \cdot 259 \mathrm{E}-03$ \\
\hline$c_{2}$ & $-2 \cdot 128 \mathrm{E}-05$ & $-1 \cdot 140 \mathrm{E}-03$ & $-1 \cdot 187 \mathrm{E}-03$ & $-2 \cdot 339 \mathrm{E}-03$ \\
\hline $\bar{d}_{0}$ & - & $-5 \cdot 701 \mathrm{E}-09$ & $1 \cdot 880 \mathrm{E}-08$ & $4 \cdot 476 \mathrm{E}-08$ \\
\hline$d_{1}$ & - & $-1 \cdot 699 \mathrm{E}-08$ & $-1 \cdot 203 \mathrm{E}-07$ & $-3 \cdot 200 \mathrm{E}-07$ \\
\hline$d_{2}$ & - & $2 \cdot 175 \mathrm{E}-07$ & $3 \cdot 197 \mathrm{E}-07$ & $6 \cdot 586 \mathrm{E}-07$ \\
\hline$R^{2}$ & 0.9917 & 0.9906 & 0.9885 & 0.9840 \\
\hline \multicolumn{5}{|l|}{ Consort } \\
\hline$a_{0}$ & $9 \cdot 90$ & $3 \cdot 22$ & $19 \cdot 24$ & $16 \cdot 02$ \\
\hline$a_{1}$ & $-99 \cdot 87$ & $-33 \cdot 63$ & $-148 \cdot 27$ & $-161 \cdot 03$ \\
\hline$a_{2}$ & $297 \cdot 39$ & $58 \cdot 54$ & $275 \cdot 20$ & $355 \cdot 90$ \\
\hline$b_{0}$ & $0 \cdot 1186$ & $0 \cdot 1113$ & $0 \cdot 1212$ & $0 \cdot 1877$ \\
\hline$b_{1}$ & -0.3148 & $-0 \cdot 2552$ & $-0 \cdot 1574$ & -0.5236 \\
\hline$b_{2}$ & $0 \cdot 0790$ & $0 \cdot 3604$ & $0 \cdot 0603$ & $0 \cdot 6046$ \\
\hline$c_{0}$ & $-3 \cdot 849 \mathrm{E}-05$ & $-3 \cdot 764 \mathrm{E}-05$ & $-7 \cdot 727 \mathrm{E}-05$ & $-1 \cdot 375 \mathrm{E}-04$ \\
\hline$c_{1}$ & 1.923E-04 & $-2 \cdot 297 \mathrm{E}-05$ & 7.914E-05 & 4.791E-04 \\
\hline$c_{2}$ & $-1.741 \mathrm{E}-04$ & $-7 \cdot 040 \mathrm{E}-05$ & $-1 \cdot 210 \mathrm{E}-04$ & $-7 \cdot 693 \mathrm{E}-04$ \\
\hline$d_{0}$ & - & 3.993E-09 & 1.794E-08 & $3 \cdot 345 \mathrm{E}-08$ \\
\hline$d_{1}$ & - & $5 \cdot 468 \mathrm{E}-08$ & $1 \cdot 690 \mathrm{E}-10$ & $-1 \cdot 199 \mathrm{E}-07$ \\
\hline$d_{2}$ & - & $-4 \cdot 075 \mathrm{E}-08$ & $1 \cdot 642 \mathrm{E}-08$ & $2 \cdot 257 \mathrm{E}-07$ \\
\hline$R^{2}$ & 0.9950 & 0.9898 & 0.9849 & 0.9794 \\
\hline
\end{tabular}

The breakage function can be obtained by differentiating $B(x, D)$ as given by equations ( 6$)$ and (7) with respect to $x$ :

$$
\begin{aligned}
\rho(x, D)= & \frac{d}{d x} B(x, D) \\
= & b_{0}+2 c_{0} x+\left(b_{1}+2 c_{1} x\right)\left(\frac{G}{D}\right) \\
& +\left(b_{2}+2 c_{2} x\right)\left(\frac{G}{D}\right)^{2} \text { for S-S } \\
\rho(x, D)= & b_{0}+2 c_{0} x+3 d_{0} x^{2} \\
& +\left(b_{1}+2 c_{1} x+3 d_{1} x^{2}\right)\left(\frac{G}{D}\right)^{2} \\
& +\left(b_{2}+2 c_{2} x+3 d_{2} x^{2}\right)\left(\frac{G}{D}\right)^{2} \\
& \quad \text { for S-D }, \text { D-S and D-D }
\end{aligned}
$$

The breakage function changes as a quadratic function of the milling ratio $(G / D)$ and output particle size $x$, except in the case of S-S, for which the breakage function is a linear function of $x$.

The cumulative output size distribution from a polydisperse feed can be predicted by inserting equation (6) or (7) into equation (4). Figure 3 compares the predictions with experimental results of milling Hereward and Consort native feed samples at different roll gaps from 0.3 to $0.7 \mathrm{~mm}$ and at the four roll dispositions. The solid lines are the predictions, based on the feed size distributions reported in Table $\mathrm{I}$, and the data points are experimental results. The comparison between predicted and experimental results gave $R^{2}$ values in excess of 0.99 for all eight cases. This demonstrates that once the breakage function is known, breakage of any size distribution of feed particles at any roll gap can be accurately predicted.

Different wheat samples have different physicochemical properties, and different roll designs and operational parameters break grains differently, 

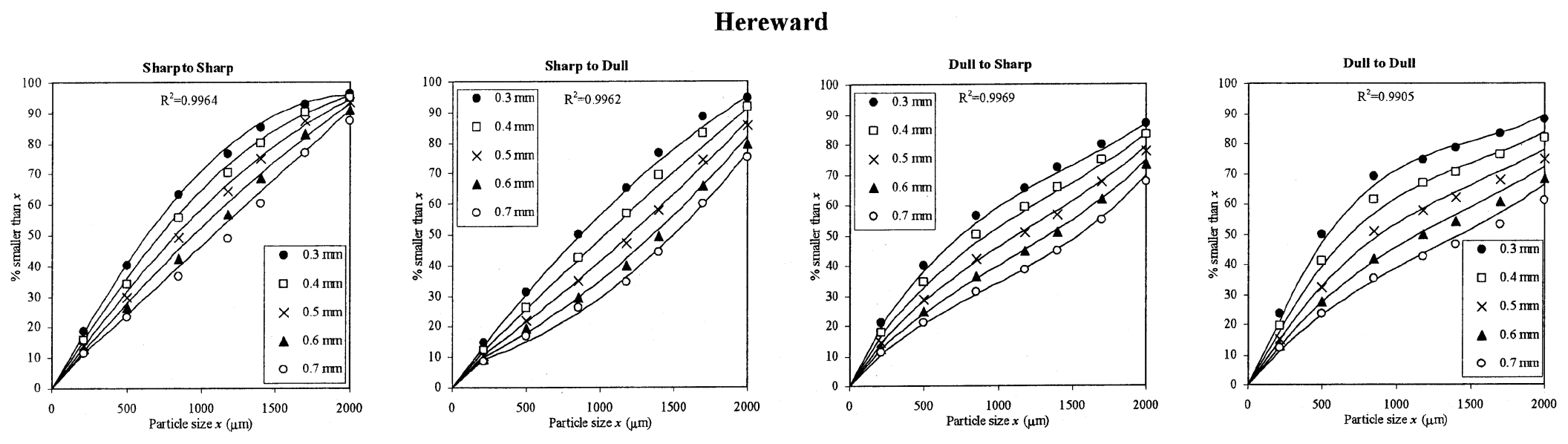

\section{Consort}
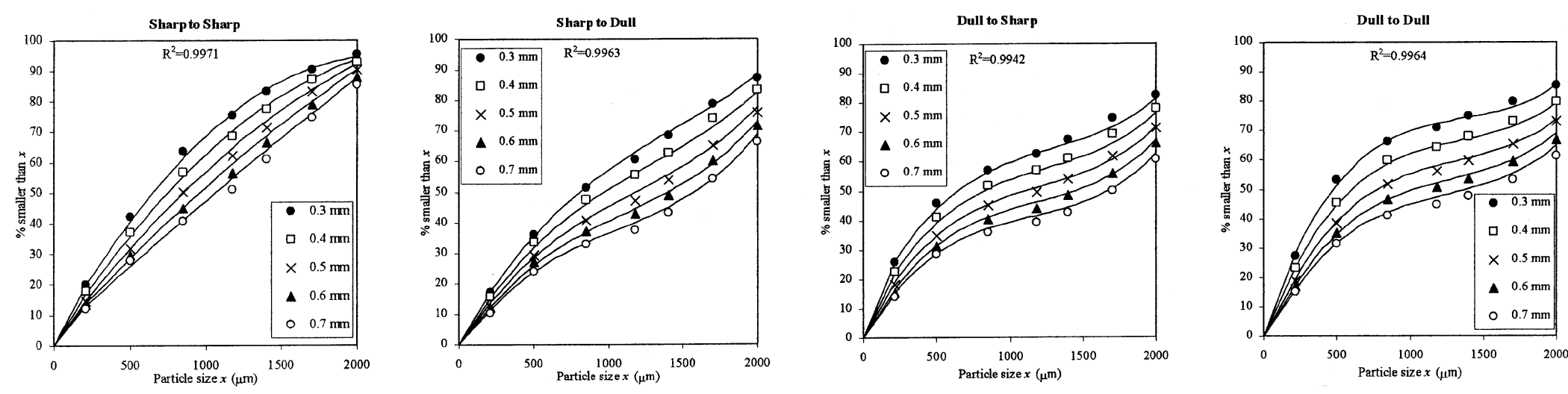

Figure 3 Cumulative particle size distributions resulting from milling Hereward and Consort at different roll gaps under S-S, S-D, D-S and D-D dispositions: comparison of predictions using the breakage functions with experimental results. 
requiring construction of the breakage function for each wheat sample and each operating condition. Nevertheless, this work has demonstrated that a simple polynomial form of the breakage function is applicable for different wheat varieties and different roll dispositions. Campbell et al. ${ }^{6}$ noted that different breakage functions could be combined to describe milling of mixtures of wheat varieties. In principle a more comprehensive breakage function could be constructed in which the coefficients could be calculated directly from knowledge of wheat physico-chemical properties and roll design and operation.

The breakage function, $\rho(x, D)$, describes the particle size distribution produced on breakage, given an initial particle size $D$. Wheat kernels in a sample differ in more than just size. Other factors affecting wheat kernel breakage include hardness $(h)$, moisture content $(m)$, protein content $(p)$ and density $(\rho)$. For given operating conditions, the breakage function could be written more generally as $\rho$ ( $x$ given $G / D, h, m, p, \rho)$. Knowing the distribution of each of these factors, breakage could in principle be predicted for any wheat, without knowing the variety, basing predictions entirely on measurement of single kernel characteristics. Extending this further, a particular grist may contain several varieties differing widely in geographical origin and physicochemical characteristics. Nevertheless, each kernel breaks independently, so provided the distributions of physico-chemical parameters affecting breakage can be measured, and suitable breakage equations constructed, the breakage pattern of any grist could in principle be predicted.

The trend in cereal quality testing is to measure distributions of single kernel parameters ${ }^{26}$, with the Perten Single Kernel Characterisation System (SKCS) the most well developed example of this concept $^{27-32}$. The SKCS measures individual kernel mass, moisture content, diameter and hardness in a sample of 300 kernels, and presents distributions of these parameters. The challenge then is to interpret these distributions of information. The breakage function approach described here is ideally suited to relating distributions of single kernel parameters to milling performance.

\section{CONCLUSIONS}

Breakage functions for First Break rolling milling of two wheat varieties at four different roll dispositions using fluted rolls have been constructed and used to predict accurately the particle size distribution resulting from milling a polydisperse mixture of feed kernel sizes. The breakage functions for different wheat varieties and roll dispositions are quantitatively different but qualitatively similar in form, varying quadratically with both milling ratio and output particle size, except for Sharp-to-Sharp milling which gave a breakage function that varied linearly with particle size. The breakage equation approach is suited to linking distributions of single kernel parameters to milling performance.

\section{Acknowledgements}

This work was funded by the Engineering and Physical Sciences Research Council (EPSRC, Grant No. GR/ M49939). The support of the Satake Corporation of Japan is gratefully acknowledged.

\section{REFERENCES}

1. Campbell, G.M., Fang, G.Y., Bunn, P.J., Gibson, A.A.G., Thompson, F. and Haigh, A. Wheat flour milling: a case study in particulate processing. In 'Powders and Solids: Developments in Handling and Processing Technology', (W. Hoyle, ed.), Royal Society of Chemistry (2001).

2. Owens, W.G. Wheat, corn and coarse grains milling. In 'Cereals Processing Technology' (W.G. Owens, ed.), Woodhead Publishing Ltd., Cambridge UK (2001) pp 27-52.

3. Smith, L. Flour Milling Technology, 3rd Ed. The Northern Publishing Co. Ltd, Liverpool, England (1944).

4. Bunn, P.J., Campbell, G.M. and Hook, S.C.W. Roller milling of wheat: towards a definition of wheat hardness. 1998 IChemE Research Event, Institution of Chemical Engineers, Rugby, UK (1998).

5. Campbell, G.M. and Webb, C. On predicting roller milling performance. I. The breakage equation. Powder Technology 115 (2001) 234-242.

6. Campbell, G.M., Bunn, P.J., Webb, C. and Hook, S.C.W. On predicting roller milling performance. II. The breakage function. Powder Technology 115 (2001) 243-255.

7. Austin, L.G. A review: introduction to the mathematical description of grinding as a rate process. Powder Technology 5 (1972) 1-17.

8. Austin, L.G., van Orden, D.R. and Perez, J.W. A preliminary analysis of smooth roll crushers. International Fournal of Mineral Processing 6 (1980) 321-336.

9. Austin, L.G., van Orden, D., McWilliams, B. and Perez, J.W. Breakage parameters of some materials in smooth roll crushers. Powder Technology 28 (1981) 245-251.

10. Rogers, R.S.C. and Shoji, K. A double-roll crusher model applied to a full scale crusher. Powder Technology 35 (1983) 123-129.

11. Klimpel, R.R. and Austin, L.G. The back-calculation of specific rates of breakage from continuous mill data. Powder Technology 38 (1984) 77-91. 
12. Rajendran Nair, P.B. Material characteristics and the breakage parameters in a circular fluid energy mill. Advanced Powder Technology 10 (1999) 21-36.

13. Scanlon, M.G. and Lamb, J. Particle size formation during food comminution operations. Powder Technology 74 (1993) 279-286.

14. Austin, L.G. and Bhatia, V.K. Experimental methods for grinding studies in laboratory mills. Powder Technology 5 (1971) 261-265.

15. Krogh, S.R. Crushing characteristics. Powder Technology 27 (1980) 171-181.

16. Gotsis, C. and Trass, O. Performance of the Szego mill in dry grinding coal and wheat. Powder Technology 41 (1985) 287-294.

17. Werner, V., Zelkowski, J. and Schonert, K. Lab-scale roller table mill for investigating the grinding behaviour of coal. Powder Technology 105 (1999) 30-38.

18. Pomeranz, Y. and Williams, P.C. Wheat hardness: its genetic, structural, and biochemical background, measurement, and significance. In 'Advances in Cereal Science and Technology, Vol 10’ (Y. Pomeranz, ed.), American Association of Cereal Chemists, St Paul, MN (1990) pp $471-548$.

19. Glenn, G.M., Younce, F.L. and Pitts, M.J. Fundamental physical properties characterizing the hardness of wheat endosperm. Fournal of Cereal Science 13 (1991) 179-194.

20. Glenn, G.M. and Johnston, R.K. Moisture-dependent changes in the mechanical properties of isolated wheat bran. Journal of Cereal Science 15 (1992) 223-236.

21. Haddad, Y., Mabille, F., Mermet, A., Abecassis, J. and Benet, J.C. Rheological properties of wheat endosperm with a view on grinding behaviour. Powder Technology 105 (1999) 89-94.

22. Mabille, F., Gril, J. and Abecassis, J. Mechanical properties of wheat seed coats. Cereal Chemistry 78 (2001) 231-235.

23. Bunn, P.J., Campbell, G.M., Fang, C.Y. and Hook, S.C.W. On predicting roller milling performance. III. The particle size distribution from roller milling of various wheats using fluted rolls. 6th World Chemical Engineering Congress, University of Melbourne, Victoria, Australia (2001).

24. Fang, C.Y. and Campbell, G.M. Effect of roll fluting disposition and roll gap on the breakage of wheat kernels during First Break roller milling. Cereal Chemistry 79 (2002) 518-522.

25. Fang, C.Y. and Campbell, G.M. Stress-strain analysis and visual observation of wheat kernel breakage during roller milling using fluted rolls. Cereal Chemistry 79 (2002) 511-517.

26. Evers, A.D. New opportunities in wheat grading. Proceedings of the 26th Nordic Cereal Congress (1996) 61-70.

27. Martin, C., Rousser, R. and Brabec, D.L. Development of a single kernel wheat characterisation system. Transactions of the American Society of Agricultural Engineers 36 (1993) 1399-1404.

28. Gaines, C.S., Finney, P.F., Fleege, L.M. and Andrews, L.C. Predicting a hardness measurement using the SingleKernel Characterisation System. Cereal Chemistry 73 (1996) 278-283.

29. Satumbaga, R., Martin, C., Eustace, D. and Deyoe, C.W. Relationship of physical and milling properties of hard red winter wheat using the Single-Kernel Wheat Characterisation System. Association of Operative Millers Bulletin, January (1995) 6487-6496.

30. Osborne, B.G., Kotwal, Z., Blakeney, A.B., O'Brien, L., Shah, S. and Fearn, T. Application of the Single-Kernel Characterisation System to wheat receiving testing and quality prediction. Cereal Chemistry 74 (1997) 467-470.

31. Deyoe, C., Chen, Y., Reddy, P.V., McCluskey, P., Gwirtz, J. and Eustace, D. Utilization of the SKWCS information in hard red winter wheat surveys for quality evaluations. Association of Operative Millers Bulletin, July (1998) 7131-7140.

32. Osborne, B.G. Wheat flour milling, Part 2. In 'Cereals and Cereal Products: Chemistry and Technology' (D.A.V. Bendy and B.J. Dobraszczyk, eds), Aspen Publishers Inc., Maryland, USA (2001) pp 172-181. 